\title{
Solvent Extraction of Platinum (IV) with 4-(4-Ethoxybenzylideneamino)-5-methyl- 4H-1,2,4-triazole-3-thiol (EBIMTT) from Hydrochloric Acid Media
}

\author{
Uzma parveen K. Shaikh, Aashish O. Dhokte, Machhindra K. Lande, and Balasaheb R. Arbad* \\ Department of Chemistry, Dr.Babasaheb Ambedkar Marathwada University, Aurangabad-431004 Maharashtra, India. \\ ${ }^{*}$ E-mail: abr_chem@yahoo.co.in
}

(Received July 4, 2011; Accepted December 16, 2011)

\begin{abstract}
The solvent extraction of platinum (IV) metal from hydrochloric acid media using 4-(4-ethoxybenzylideneamino)-5-methyl-4H-1,2,4-triazole-3-thiol (EBIMTT) in chloroform was studied as a function of several variables, such as reagent, acid and metal ion concentration, effect of various diluents, and diverse ions. The proposed method was further applied for the separation of platinum (IV) from binary mixtures, synthetic mixtures, alloys and commercially available samples.
\end{abstract}

Key words: Solvent extraction, Pt (IV), EBIMTT, Real samples

\section{INTRODUCTION}

Platinum is an extremely rare metal, occurring at a concentration of only $0.005 \mathrm{ppm}$ in the earth's crust. ${ }^{1}$ The most common uses of platinum are in electronic industries, in automotive exhaust-gas control converters and as a catalyst in petroleum and chemical processes. Due to its scarcity and importance there is need to recycle the platinum metal from secondary sources like electronic scrap, petrochemical catalysts, automotive catalysts. ${ }^{2}$

Usually, before the spectrophotometric determination of each metal, a separation is imperative and the separation step definitely represents the most difficult problem of the analysis, especially in the case of trace amounts. From this point of view, the solvent extraction technique holds a prominent position among separation techniques because of its speed, ease and selectivity. Liquid-liquid extraction procedures have proven very useful in the separation of metal ions.

During the last three decades a variety of extractants have been proposed for the solvent extraction of platinum (VI), like Cyanex-923, ${ }^{3}$ Cyclic tetrathioethers, ${ }^{4}$ 2-mercaptobenzothiazole, ${ }^{5}$ Organoaminophosphonate, ${ }^{6}$ Tri-nbutyl Phosphate, ${ }^{7}$ N,N-di-n-hexyl-Nbenzoylthiourea, ${ }^{8} \mathrm{~N}, \mathrm{~N}-$ Nonylthiourea, ${ }^{9}$ diethyl-N-benzoylthiourea, ${ }^{10}$ Bis (2-ethylhexyl $){ }^{11}$ Dialkyl sulphoxide, ${ }^{12} \mathrm{~N}$-octylaniline, ${ }^{13}$ tri-isooctylamine. ${ }^{14}$

Sulphur containing ligands showed promising effects in the field of analytical chemistry for the separation and estimation of platinum group metals. ${ }^{15,16}$ As a soft acid, platinum has a great affinity for soft base ligand containing sulfur. Hence, a new extractant has been synthesized containing sulphur and nitrogen as donor atoms, 4-(4ethoxybenzylideneamino)-5-methyl-4H-1,2,4-triazole-3thiol (EBIMTT), and its effectiveness has been evaluated as an extractant for Pt(IV) from alloys, synthetic mixtures and real samples.

The important features of this method are that, it permits selective separation of Pt(IV) from other platinum group metals and base metals which are generally associated with it. It is free from interference from a large number of foreign ions, low reagent concentration is required and time needed for equilibration is short (about just $30 \mathrm{sec}-$ onds). We report here the use of EBIMTT as an excellent extractant for Pt(IV) from hydrochloric acid medium.

\section{EXPERIMENTAL}

\section{Instrumentation}

A Jasco V-530 UV-Vis spectrophotometer with $1 \mathrm{~cm}$ quartz cells was used for absorbance measurement, $\mathrm{pH}$ measurements were carried out with an Elico digital $\mathrm{pH}$ meter model LI-120 $( \pm 0.01)$.

\section{Reagents}

Synthesis of extractant: Precursor, 3-ethyl-4-amino-5mercapto-1,2,4-triazole was synthesized and recrystallized as reported by ${ }^{17,18}$ which was reacted with 0.02 mole of ethoxybenzaldehyde in $50 \mathrm{ml}$ alcohol containing 3 drops of glacial acetic acid and was refluxed for 3-4 h. ${ }^{19}$ The product obtained was separated and recrystallized from hot ethanol as pale yellow shiny needles (m.p. $171{ }^{\circ} \mathrm{C}$ ) Fig. 1.

${ }^{1} \mathrm{H}-\mathrm{NMR}$ spectra of synthesized extractant was recorded 


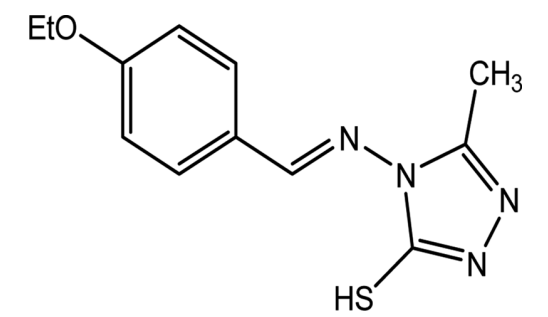

Fig. 1. Structure of 4-(4-ethoxybenzylideneamino)-5-methyl-4H1, 2, 4-triazole -3-thiol (EBIMTT).

in $\mathrm{CDCl}_{3}$. It shows following signals at. $2.12\left(5 \mathrm{H}, \mathrm{s},-\mathrm{C}_{2} \mathrm{H}_{5}\right)$, $6.8(2 \mathrm{H}, \mathrm{d}$, aromatic protons), 7.5 (2H, d, aromatic protons), 8.1(1H, s,-CH), 3.08 (1H, s, -SH). Mass spectral data of the ligand has been recorded and shows the molecular ion peak $(\mathrm{M}+)$ at $\mathrm{m} / \mathrm{z}=262.09$ as indicated by the peaks corresponding to their molecular masses. The FT-IR spectrum of the free extractant shows $\mathrm{C}-\mathrm{H}$ stretching at 2885 $\mathrm{cm}^{-1},-\mathrm{C}=\mathrm{N}$ stretching at $1600 \mathrm{~cm}^{-1}$ and $754 \mathrm{~cm}^{-1}$ for $-\mathrm{C}=\mathrm{S}$.

Solutions with a desired concentration of EBIMTT were prepared by dissolving appropriate amount of EBIMTT in chloroform. A stock solution of $\mathrm{Pt}(\mathrm{IV})$ was prepared by dissolving $1 \mathrm{~g}$ of Platinum(IV) chloride hydrate $\left(\mathrm{PtCl}_{4}\right)$ in analytical reagent hydrochloric acid (1M) diluted to 100 $\mathrm{ml}$ with double distilled water. The required concentration of this solution was prepared by further dilution. Other standard solutions of different metal ions used to study the effect of foreign ions were prepared by dissolving weighed quantities of respective salts in distilled water or dilute hydrochloric acid. All the chemicals used were of analytical grades. Double distilled water was invariably used throughout the measurements.

\section{Recommended procedure}

An aqueous solution containing $200 \mu \mathrm{g}$ Pt(IV) mixed with a sufficient quantity of hydrochloric acid and water were added to give final concentration of $1 \mathrm{M}$ with respect to hydrochloric acid in $25 \mathrm{ml}$. Then the $\mathrm{pH}$ of the solution was adjusted to 1.0 using dilute hydrochloric acid and sodium hydroxide. The solution was transferred into a $125 \mathrm{ml}$ separating funnel and shaken with $10 \mathrm{ml}$ of $0.1 \mathrm{MEBIMTT}$ in chloroform for just 30 seconds. After equilibration, the mixture was allowed to separate and the metal was stripped from the organic phase with two $10 \mathrm{ml}$ portions of water. The extracts were evaporated to moist dryness. The residue was dissolved in $5 \mathrm{ml}$ of conc. hydrochloric acid and 10 $\mathrm{ml}$ of $20 \% \mathrm{Sncl}_{2}$ (stannous chloride) was added. The solution was diluted to the mark with water. The absorbance of the resulted solution was measured at $403 \mathrm{~nm} .{ }^{20}$ The concentration of $\mathrm{Pt}(\mathrm{IV})$ was found from a calibration curve.

\section{RESULT AND DISCUSSION}

Effect of solvent: Among organic solvents (benzene, chloroform, acetone, carbon tetrachloride, nitrobenzene, isobutyl alcohol, 1-butanol, isobutyl methyl ketone, ethanol, 1.4-dioxan and N, Ndimethylformamide) were examined for the extraction of Pt(IV) with EBIMTT from hydrochloric acid media, chloroform medium extracts the complex effectively without third phase formation.

Extraction as a function of pH: Platinum (IV) was extracted in the $\mathrm{pH}$ range of 0.1-9 in the presence of $1 \mathrm{M}$ hydrochloric acid. The quantitative extraction was obtained at $\mathrm{pH}$ range $1-2$. The maximum absorption was observed at pH 1 (Fig. 2).

Effect of acids: Extraction of Platinum (IV) was carried out in different acid media like hydrochloric acid, sulphuric acid, nitric acid, hydrochloric acid showed good extraction properties, while nitric acid forms emulsion at the time of extraction. Due to maximum extraction and better phase separation hydrochloric acid was found to be appropriate medium for extraction of Pt(IV) (Table 1).

Effect of reagent concentration: Different molar excess of EBIMTT were added to a fixed metal ion concentration and the absorbances were measured according to the standard procedure.

It was observed that $0.06 \mathrm{M}$ EBIMTT was sufficient for quantitative extraction of $200 \mu \mathrm{g}$ of $\mathrm{Pt}(\mathrm{IV})$, but in recommended procedure, $10 \mathrm{~mL}$ of $0.1 \mathrm{M}$ EBIMTT in chloro-

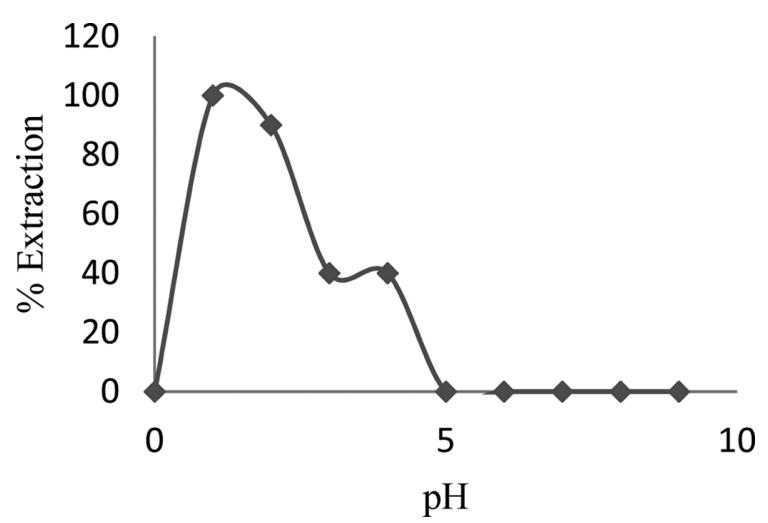

Fig. 2. Extraction of platinum (IV) with $0.1 \mathrm{M}$ EBIMTT from hydrochloric acid medium as a function of $\mathrm{pH}$.

Table 1. Extraction of Pt(IV) from different acid media with EBIMTT in chloroform

\begin{tabular}{cc}
\hline Acid media & \% Extraction \\
\hline Hydrochloric acid & 99 \\
Nitric acid & 20 \\
Sulphuric acid & 15 \\
\hline
\end{tabular}




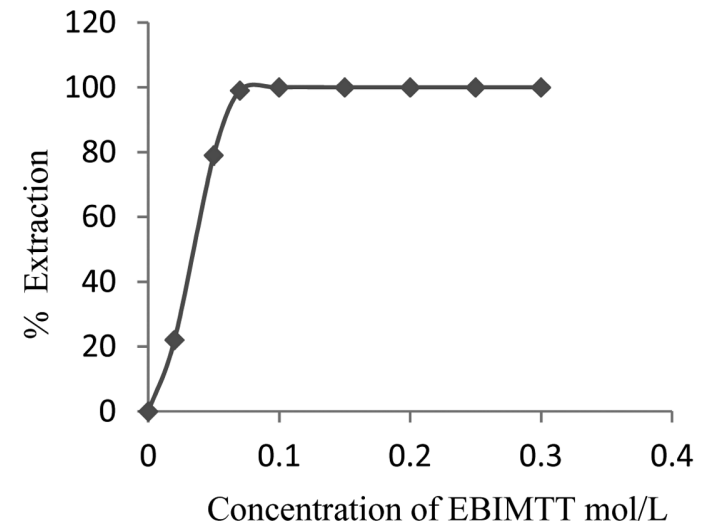

Fig. 3. Extraction of platinum (IV) at $\mathrm{pH} 1.0$ from hydrochloric acid medium as a function of EBIMTT concentration.

Table 2. Table of tolerance limit of foreign ions (diverse ions) on $200 \mu \mathrm{g}$ of Pt (IV) from hydrochloric acid with 0.1 M EBIMTT in chloroform

\begin{tabular}{|c|c|c|c|}
\hline $\begin{array}{c}\text { foreign ions } \\
\text { added }\end{array}$ & $\begin{array}{c}\text { Amount } \\
\text { tolerated }(\mathrm{mg})\end{array}$ & $\begin{array}{c}\text { foreign ions } \\
\text { added }\end{array}$ & $\begin{array}{c}\text { Amount } \\
\text { tolerated (mg) }\end{array}$ \\
\hline $\mathrm{Au}^{\text {IIIa }}$ & 0.5 & $\mathrm{Fe}^{\mathrm{III}}$ & 15 \\
\hline $\mathrm{Pd}^{\mathrm{IIa}}$ & 0.5 & $B i^{I I I}$ & 15 \\
\hline $\mathrm{Rh}^{\text {IIIa }}$ & 0.5 & $\mathrm{Mg}^{\mathrm{II}}$ & 15 \\
\hline $\mathrm{Cu}^{\mathrm{II}}$ & 15 & $\mathrm{Ba}^{\mathrm{II}}$ & 20 \\
\hline $\mathrm{Ni}^{\mathrm{II}}$ & 10 & $\mathrm{Be}^{\mathrm{II}}$ & 20 \\
\hline $\mathrm{Sn}^{\mathrm{II}}$ & 10 & $\mathrm{Ca}^{\mathrm{II}}$ & 20 \\
\hline $\mathrm{Mo}^{\mathrm{VI}}$ & 20 & $\mathrm{Mn}^{\mathrm{II}}$ & 15 \\
\hline $\mathrm{Cd}^{\mathrm{II}}$ & 10 & Acetate & 100 \\
\hline $\mathrm{Pb}^{\mathrm{II}}$ & 10 & Bromid & 100 \\
\hline $\mathrm{Hg}^{\mathrm{II}}$ & 10 & Tartarate & 100 \\
\hline $\mathrm{Sb}^{\mathrm{III}}$ & 15 & EDTA & 100 \\
\hline
\end{tabular}

${ }^{a}$ Masked with tartrate

form was used to ensure the complete extraction of metal ion (Fig. 3).

Effect of diverse ions: The effect of various diverse ions was tested, when platinum (IV) was extracted with EBIMTT in chloroform. The tolerance limit of individual diverse ions was determined with an error less than $\pm 2 \%$. It was observed that the method is free from interference from a large number of cations and anions (Table 2). The only species showing interference in the procedure were $\mathrm{Pd}(\mathrm{II})$, $\mathrm{Rh}(\mathrm{III})$ and $\mathrm{Au}(\mathrm{III})$. However, the interference of Pd(II) and $\mathrm{Rh}(\mathrm{III})$ was eliminated by masking with tartrate.

Effect of stripping agents: Platinum (IV) was stripped with different stripping agents such as mineral acids, bases, and salts after its extraction. The stripping of platinum (IV) was quantitative with water. The stripping was found to be incomplete with ammonia $(60 \%)$, and sodium chloride (40\%), with hydrochloric acid (20\%), whereas platinum (IV) was not stripped with sulphuric acid and sodium hydroxide.

Effect of shaking time: The effect of time on extraction of Pt(IV) was observed for a period of $5 \mathrm{sec}$. to $30 \mathrm{~min}$. The extraction was found quantitative in the period of 1035 seconds. Prolonged shaking has no adverse effect on the extraction, but to ensure the complete extraction $1 \mathrm{~min}$ equilibration time was selected.

Applications: The present method was successfully applied for the determination of Platinum (VI) in a series of synthetic mixtures of various compositions, and also in a number of real samples, e.g. several Certified Reference Materials (CRMs).

1) Binary separation of Pt(IV) from iron(III), cobalt(II), nickel(II) and copper(II): The method allowed separation and determination of $\mathrm{Pt}(\mathrm{IV})$ from a binary mixture containing either iron(III), cobalt(II), nickel(II) and copper(II). In a typical experiment, solution containing $200 \mu \mathrm{g}$ of Pt (IV) was taken and known amounts of other metals were added. The separation of Pt (IV) from iron(III), cobalt(II), nickel(II) and copper(II) was accomplished with $0.1 \mathrm{~mol} / \mathrm{dm}^{3}$ EBIMTT in chloroform at $1 \mathrm{~mol} / \mathrm{dm}^{3}$ hydrochloric acid. Pt(IV) was estimated spectrophotometrically by stannous chloride method. The recovery of Pt(IV) and that added ions was $99.5 \%$ and results are reported in (Table 3).

2) Analysis of synthetic mixtures corresponding to alloy: The method was applied for the analysis of synthetic mixtures. Synthetic mixtures corresponding to alloys were prepared and analyzed for Pt(IV) content. Platinum (IV) was recovered quantitatively from hydrochloric medium by the proposed method. The method is selective and permits rapid separation and determination of micro amounts of Pt(IV). The average recovery of Pt(IV) was $99.5 \%$ (Table 4).

3) Real sample analysis: EBIMTT also separates Pt(IV) from real samples like rhodium-platinum thermocouple wire, this platinum base alloy containing more than $10 \%$ of iridium and rhodium. An aliquot of the real sample was prepared by the procedure given by Kolekar ${ }^{21}$ and Pt(IV)

Table 3. Binary separation of Pt (IV) from iron(III), cobalt(II), nickel(II) and copper(II)

\begin{tabular}{ccc}
\hline $\begin{array}{c}\text { Composition of metal ions } \\
(\mu \mathrm{g})\end{array}$ & $\begin{array}{c}\text { Recovery } \\
\mathrm{Pt}(\mathrm{IV})(\%)\end{array}$ & $\begin{array}{c}\text { Relative standard } \\
\text { deviation }(\%)\end{array}$ \\
\hline Pt(IV); 200, Fe(III); 15000 & 99.8 & 0.13 \\
$\mathrm{Pt}(\mathrm{IV}) ; 200, \mathrm{Co}(\mathrm{II}) ; 10000$ & 99.4 & 0.10 \\
$\mathrm{Pt}(\mathrm{IV}) ; 200, \mathrm{Cu}(\mathrm{II}) ; 5000$ & 99.6 & 0.15 \\
Pt(IV); 200, Ni(II); 5000 & 99.6 & 0.15 \\
\hline${ }^{*}$ Average of six determination. & &
\end{tabular}


Table 4. Analysis of synthetic mixtures corresponding to alloy

\begin{tabular}{cccccc}
\hline Alloy & Composition $(\%)$ & Platinum taken $(\mu \mathrm{g})$ & Platinum found $(\mu \mathrm{g})$ & Recovery* $(\%)$ & R.S.D (\%) \\
\hline Platinurn-rhodium alloy & 90Pt, 10Rh & 200 & 199 & 99.5 & 0.09 \\
Cooper's pen metal & 50Pt, 38Ag, 12Cu & 200 & 199.8 & 99.9 & 0.06 \\
Cooper's gold & $67-81 \mathrm{Cu}, 19-30 \mathrm{Pt}, 0-4 \mathrm{Zn}$ & 200 & 199.8 & 99.9 & 0.06 \\
Platinum substitute, electrical & 68Au, 25Ag, 7.5Pt & 200 & 199.8 & 99.9 & 0.06 \\
Oakay alloy & 20Pt, 10.5Pd, 60Ni, 9.5V & 200 & 199.7 & 99.8 & 0.07 \\
Solder alloy & 10Pt, 30Pd, 60Au & 200 & 199.8 & 99.9 & 0.06 \\
\hline
\end{tabular}

Table 5. Analysis of real samples for platinum content

\begin{tabular}{ccccc}
\hline Sample & $\begin{array}{c}\text { Composition } \\
(\%)\end{array}$ & $\begin{array}{c}\text { Certified value of } \\
\text { platinum }\end{array}$ & $\begin{array}{c}\text { Amount of platinum(IV) found by } \\
\text { proposed method }\end{array}$ & $\begin{array}{c}\text { R.S.D } \\
(\%)\end{array}$ \\
\hline Platinum-rhodium thermocouple wire & $87 \mathrm{Pt}, 13 \mathrm{Rh}$ & $87 \%$ & $86.6 \%$ & 0.30 \\
\hline
\end{tabular}

was determined using the procedure given above. The results of analysis are given in Table 5.

\section{CONCLUSION}

EBIMTT has been proved to be a sensitive and selective spectrophotometric reagent for Pt(IV), it can be synthesized at low cost with high yield and in the best purity and recovered for reuse without loss of extraction efficiency. The proposed method is simple, reproducible and rapid. The important features of the method are, it permits selective separation and determination of $\operatorname{Pt}(\mathrm{IV})$ from other associated metals such as $\mathrm{Cu}(\mathrm{II}), \mathrm{Co}(\mathrm{II}), \mathrm{Pt}(\mathrm{IV})$, $\mathrm{Ru}(\mathrm{III}), \mathrm{Fe}(\mathrm{III}), \mathrm{Pd}(\mathrm{II}), \mathrm{Ni}(\mathrm{II})$, low reagent concentration is required for quantitative recovery of $\mathrm{Pt}(\mathrm{IV})$, shorter time of equilibration was needed, it is free from interference of a large number of foreign ions which are associated with $\mathrm{Pt}(\mathrm{IV})$ in its natural occurrence and it is successfully applicable to the determination of Pt(IV) in analysis of binary, synthetic mixtures and real samples.

Acknowledgment. The authors are thankful to UGC New Delhi for providing financial assistance through MANF scheme and the Head, Department of Chemistry, Dr. Babasaheb Ambedkar Marathwada University, Aurangabad, for providing necessary facilities.

\section{REFERENCES}

1. Murata, K. J. Symposium on Spectrocemical Analysis for Trace Elements: 1958; p 71.

2. Goralska, E.; Coll, M.T.; Fortuny, A.; Kedari, C.S.; Sastre, A.M. Solvent Extr. Ion Exch. 2007, 25, 65.
3. Duchea, S. N.; Dhadke, P. M. Sep. Sci. Tech. 2002, 37, 3011.

4. Keiitsu, S.; Ichiro T.; Yasuyo Y.; Satomi, M.; Akihiko, M. Talanta 2000, 51, 913.

5. Diamantatos, A. Analytica Chimicu Acta 1973, 66, 147.

6. Keisuke, O.; Junji, N.; Seiji, H.; Kazuharu,Y.; Katsutoshi, I.;Yoshinari, B. Solvent Extr. Ion Exch 1997, 15, 115.

7. Faye, G. H.; Inman, W. Anal. Chem. 1963, 35, 8.

8. Vest, P.; Schuster, M.; Honig, K. Fres. J. Anal. Chem. 1991, 339, 142.

9. Uheida, A.; Zhang, Y.; Muhammed, M. Solvent Extr. Ion Exch. 2003, 21, 827.

10. Merdivan, M.; Aygun, R. S.; Kulcu, N. Annali di Chimica 2000, 90, 407.

11. Sherikar, A. V.; Phalke, P. N. Dhadke, P. M. Bull. Chem. Soc. Jpn. 1997, 70, 805.

12. John, S. P.; Anna, C. du Preez, Solvent Extr. Ion Exch. 2002, 20, 359.

13. Lokhande, T. N.; Anuse, M. A.; Chavan, M. B. Talanta 1998, 47, 823 .

14. Lee, J. Y.; Rajesh, K. J.; Kim, J. S.; Park, H. K.; Yoon, H. S. J. Hazard Mater. 2009, 168, 424.

15. Vest, P.; Schuster, M.; Konig, K. H. Fres. J. Anal. Chem. 1989, 335, 759.

16. Inoue, K.; Koba, M.; Yoshizuka, K. Solvent Extr. Ion Exch. 1994, 12, 55.

17. Dhakha, K. S.; Mohan, J.; Chanda, V. K.; Pujari, H. K. Ind. J. Chem. 1974, 12, 288.

18. Vidhate, K. N.; Lande, M. K.; Arbad, B. R. J. Ind. Chem. Soc. 2008, 85, 536.

19. Shaikh, U. P.; Katkar, S. S.; Vidhate, K. N.; Lande, M. K.; Arbad, B. R. J. Indian Chem. Soc. 2011, 88, 1.

20. Beamish, F. E.; Van Loon, J. C. Analysis of Noble Metals: Overview and Selected Methods; Academic Press: London, 1977.

21. Kolekar, S. S.; Anuse, M. A. Talanta 2002, 58, 761. 